2 Seligman MEP. The effectiveness of psychotherapy: The Consumer Reports study. Amer Psychol 1995; 50: 965-74.

3 Zelen M. A new design for randomized clinical trials. N Engl J Med 1979; 300 $1242-5$

4 Maclehose RR, Reeves BC, Harvey IM, Sheldon TA, Russell IT, Black AMS. A systematic review of comparisons of effect sizes from randomised and non-randomised studies. Health Technol Assess 2000; 4: 1-154.

Christian Gold, GAMUT, Uni Health, Lars Hilles gt. 3, 5015 Bergen, Norway, email: christian.gold@uni.no; Jaakko Erkkilä, Finnish Centre of Excellence in Interdisciplinary Music Research, University of Jyvaskyla, Finland

doi: 10.1192/bjp.199.6.515

\section{Praying with patients: belief, faith and boundary conditions}

The debate between Professors Poole and Cook $^{1}$ focuses on what might be termed an epiphenomenon of faith. Poole in particular avoids any interpretation of the values he espouses for psychiatry as a belief system. In my view, this is fundamentally erroneous. The set of principles avowed by Poole find their origin in both Greek philosophy and in the Judaeo-Christian system of ethics. These are essentially systems of beliefs and in that sense, particularly for the secularist, are no different from a religious doctrine. In considering this issue it is impossible to start from a position that does not invoke shared belief, and that personal position of belief that is termed faith. I would assume that Poole would take the position that psychiatrists should practise using 'evidence-based' techniques and therapies. If one is to take cognitive therapies as an example of this, problems of belief immediately arise, as a primary aim is to change patients' erroneous and maladaptive belief systems. I would ask to what belief system should one change them? Should it reflect the psychiatrist's beliefs, the patient's community and cultural beliefs or something else?

A common example of the integral involvement of belief with therapy is the Alcoholics Anonymous programme. Would Poole refer a patient to this as part of his treatment or would he regard it as the unethical imposition of a belief in a 'higher power'? More broadly, in psychotherapy there exist a number of theoretical belief systems which have some level of evidence in their favour, particularly in the belief of their proponents. Having observed successful psychotherapists with a variety of backgrounds, I am tempted to say that their theories support their therapies by providing a belief structure that supports their faith that treatment can be of benefit when progress is slow, and that this faith in the future is a key element in their success. If the argument that faith is a fundamental part of the treatment process is accepted, and I would argue that, while this is particularly so for psychiatry it also applies in other areas of medicine, then the major question is the degree to which it is synonymous with belief. If faith provides strength and purpose to both psychiatrist and patient and can be asserted a positive asset without much criticism, belief can be considered as being more problematic and potentially dangerous. In a broad sense, depressive disorders may be considered to reflect a deficit of faith, whereas mania and psychoses reflect an excess of belief. This may apply to therapists as much as patients. Doctors with a high level of belief in particular therapeutic modalities have a history of causing harm as well as good. An uncritical belief in materialism and biological determinism can cause as many, if not more, problems than a Cartesian view.

It seems that the divergence of opinion between Professors Poole and Cook arises not from the potential for good but the potential for harm. Both are men of belief and even if their beliefs are considered existentially 'good', assertion that an atheistic belief system is the only basis for treatment is potentially treacherous if imposed on a patient. Even our present evidence-based structure is predicated on a belief about an organised and regular universe. Speaking as a slightly irreverent theist, I would argue that the question posed in their debate does not have a single correct answer. In judging the most appropriate manner of dealing with a particular situation, the important thing is to consider the principles to be applied. There are some behaviours that would be generally agreed to be inappropriate and damaging without recourse to argument, but others may be appropriate only in certain situations. My recommendation would be that there should not be an overall statement or conclusion that the use of prayer in therapy is either right or wrong. It would have to be considered as an uncommon and unusual part of a therapeutic programme which can only be justified in very particular circumstances. It should be accepted that there are occasions when its use is appropriate and therapeutic. Nonetheless, because of its controversial nature, and the possibility of abuse by both therapist and patient, prayer should be considered an unusual therapeutic modality. The therapist should therefore be prepared to justify its use on a case-by-case basis and be able to demonstrate that no harm was likely to arise.

1 Poole R/Cook CCH. Praying with a patient constitutes a breach of professional boundaries in psychiatric practice (debate). Br J Psychiatry 2011; 199: 94-8.

Gordon R. W. Davies, University of Wollongong, 33 Smith Street, Wollongong, NSW 2500, Australia. Email: alienist@ihug.com.au

doi: 10.1192/bjp.199.6.516

I read with interest the debate between Professors Poole and Cook in this month's journal. ${ }^{1}$ I have been following the exchanges on these two highly polarised positions in the College for quite a while. Not wishing to take a position on the acceptability of praying with patients, I find myself astounded by the inability in some quarters to accept or even recognise the fact that praying with a patient may be as serious as preaching to a patient. Boundaries are set in professional practice to protect both the patient and the doctor. Would a physician feel easy taking stock market tips from their Wall Street banker patient? Or accepting racing tips from their very informed bookmaker patient? How about setting up a business venture with a venture capitalist patient with significant 'daddy issues'?

Would it be appropriate for a doctor to tell his patient that his Church offers the best chance of redemption, or that she should divorce her cheating husband because this is what is perpetuating her depression? These are all hypothetical examples of boundary violations and are rightly proscribed in all codes of ethics worldwide. In deciding harm in a doctor-patient interaction, surely it is for the doctor to decide where the boundary lies and then to maintain it. The sexual boundary is not the only boundary we should be taught not to cross, although arguably it ought to be the first.

The fact the College has given so many column inches to the issue means that, even if there are no cogent arguments, this matter is something that has immense political clout. Matters are not being helped by letting this issue simmer. We need decisive action. Why can't the College commission a working group representing all sides of this debate and issue a consensus statement to help believers and non-believers equally to navigate what appears not so much a moral conundrum as political posturing? When I am hauled before the GMC by a patient for inviting him (and encouraging with his 'consent') to give up his 